\title{
Produtividade de cereais de inverno de duplo propósito na depressão central do Rio Grande do Sul ${ }^{1}$
}

\section{Gilmar Roberto Meinerz², Clair Jorge Olivo3, Renato Serena Fontaneli4, Carlos Alberto Agnolin $^{2}$, Tiago Horst ${ }^{5}$, Cláudia Marques de Bem ${ }^{5}$}

\footnotetext{
${ }^{1}$ Pesquisa financiada com recursos do Conselho Nacional de Desenvolvimento Científico e Tecnológico - CNPq.

2 Programa de Pós-graduação em Zootecnia, Universidade Federal de Santa Maria (UFSM), RS, Brasil, 97105-900.

${ }^{3}$ Departamento de Zootecnia, UFSM, RS, Brasil.

${ }^{4}$ Embrapa Trigo - Passo Fundo, RS, Brasil.

${ }^{5}$ Curso de graduação em Zootecnia, UFSM.
}

RESUMO - Esta pesquisa foi conduzida com o objetivo de avaliar a precocidade, a produtividade e as características do dossel de 12 genótipos de seis espécies de cereais de inverno de duplo propósito (forragem e grãos) submetidos ao corte na região da Depressão Central do Rio Grande do Sul. As espécies e os genótipos testados foram: trigo BRS 277, BRS Guatambu, BRS Tarumã, BRS Umbu; aveia-preta Agro Zebu, UPFA 21 - Moreninha e Comum; aveia-branca UPF 18; centeio BR 1 e BRS Serrano; Cevada BRS Marciana; e triticale BRS 148. Os genótipos foram distribuídos em 36 parcelas experimentais, num delineamento inteiramente casualizado, com 12 tratamentos, três repetições e medidas repetidas no tempo. As variáveis estudadas foram massa de forragem, composição botânica e estrutural, produção de forragem e de grãos. Os genótipos mais precoces para produção de forragem foram o centeio BR 1 e o triticale BRS 148. O trigo BRS Tarumã apresentou maior produção de forragem e de lâminas foliares e o trigo BRS Umbu maior produção de grãos e peso do hectolitro. Entre os genótipos avaliados, o trigo BRS Tarumã é o mais indicado para duplo propósito na Depressão Central do Rio Grande do Sul.

Palavras-chave: forragem, grãos, integração lavoura-pecuária, precocidade

\section{Productivity of double-purpose winter cereals in the Depressão Central region of Rio Grande do Sul state}

\begin{abstract}
The objective of this research was to evaluate early growth, yield and canopy characteristics of 12 genotypes of six species of winter cereals with double purpose (forage and grains) submitted to harvest at Depressão Central region of Rio Grande do Sul state, South Region of Brazil. Species and genotypes tested were: BRS 277, BRS Guatambu, BRS Tarumã and BRS Umbu wheat; Agro Zebu, UPFA 21 - Moreninha and Commom black-oat; UPF 18 white-oat; BR 1 and BRS Serrano rye; BRS Marciana barley; and BRS 148 triticale. The genotypes were distributed in 36 experimental plots, in a completely randomized design with 12 treatments, three replications and repeated measure. Studied variables were herbage mass, botanical and structural composition, forage and grains production. The earliest genotypes for forage production were BR 1 rye and BRS 148 triticale. BRS Tarumã wheat presented higher forage and leaf blade production. BRS Umbu wheat presented higher grains yield and hectoliter weight. Among the genotypes evaluated, BRS Tarumã wheat is the most suitable for double purpose in Depressão Central region of Rio Grande do Sul state.
\end{abstract}

Key Words: early growth, forage, grains, livestock-crop production system

\section{Introdução}

No Sul do Brasil, uma das maiores limitações da atividade pecuária é a carência de forragem no período entre o outono e início do inverno, que ocasiona quedas na produção de leite e de carne. Para diminuir este problema, normalmente adota-se a suplementação com silagem, feno ou concentrados (Rocha et al., 2003), que implica maiores custos de produção. Neste sentido, a utilização de pastagens anuais de inverno é uma alternativa de produção de forragem precoce com menor custo.

Os cereais de inverno normalmente são cultivados com o objetivo de produzir grãos para a alimentação humana e animal ou como forrageiras para formação de pastagens. As espécies mais cultivadas são a aveia-branca (Avena sativa L.), a aveia-preta (Avena strigosa Schreb.), o centeio (Secale cereale L.), a cevada (Hordeum vulgare L.), o triticale (X Triticosecale Wittmack) e o trigo (Triticum sativum L.), 
que também podem ser utilizados como espécies de duplo propósito, produzindo forragem precoce e ainda grãos, com baixo custo, contribuindo para maior estabilidade da produção (Bortolini et al., 2004).

Dentro dessa perspectiva, e considerando as diferenças edafoclimáticas entre as regiões, avaliar essas culturas em manejo de duplo propósito é muito importante. Por serem espécies anuais, com ciclos produtivos mais curtos em relação às forrageiras perenes, a avaliação de diferentes genótipos é fundamental para determinar a variabilidade existente entre eles (Scheffer-Basso et al., 2004). Assim, objetivou-se com este trabalho avaliar a precocidade, a produtividade e as características do dossel de cereais de inverno de duplo propósito na região da Depressão Central do Rio Grande do Sul.

\section{Material e Métodos}

A pesquisa foi conduzida entre março e outubro de 2008 no Laboratório de Bovinocultura de Leite da Universidade Federal de Santa Maria (UFSM), localizado na região fisiográfica denominada Depressão Central do Rio Grande do Sul, com altitude de $95 \mathrm{~m}$, latitude $29^{\circ} 43^{\prime}$ Sul e longitude $53^{\circ} 42^{\prime}$ Oeste. O clima da região é o Cfa (subtropical úmido), conforme classificação de Köppen. Foram testadas 12 cultivares de seis espécies de cereais de inverno de duplo propósito de utilização: trigo (BRS 277, BRS Guatambu, BRS Tarumã, BRS Umbu); aveia-preta (Agro Zebu, UPFA 21 Moreninha e Comum); aveia-branca (UPF 18); centeio (BR 1 eBRS Serrano); cevada (BRS Marciana); e triticale (BRS 148).

A área experimental foi de $672 \mathrm{~m}^{2}$, divididos em 36 parcelas experimentais distribuídas ao acaso, com dimensões de $5 \mathrm{~m}$ de comprimento e $3 \mathrm{~m}$ de largura, com corredores de 0,5 $\mathrm{m}$ de largura entre elas. A semeadura foi feita em 10 de abril, em linhas com espaçamento de $17 \mathrm{~cm}$ e densidade de 400 sementes viáveis $/ \mathrm{m}^{2}$, provenientes do Centro Nacional de Pesquisa do Trigo, em Passo Fundo, Rio Grande do Sul. Trinta dias antes da semeadura foi realizada a correção da acidez, conforme a análise do solo, mediante a aplicação de calcário dolomítico do tipo Filler, incorporado mediante escarificação do solo. A adubação potássica e fosfórica e a correção da acidez foram feitas conforme as recomendações da Comissão de Química e Fertilidade do Solo - RS/SC (2004). A adubação nitrogenada, à base de ureia, foi realizada com $120 \mathrm{~kg} / \mathrm{ha}$ de $\mathrm{N}$ para todas as espécies, divididos igualmente em três aplicações. A primeira foi realizada 30 dias após a emergência das plantas, por ocasião do perfilhamento, e as aplicações restantes foram feitas após o primeiro e o segundo cortes. Também foram feitas duas aplicações de fungicida à base de Tebuconazole
(0,75 L/ha), na concentração de $250 \mathrm{~g} / \mathrm{L}$, a primeira entre o primeiro e segundo cortes e a segunda na fase de floração.

As forrageiras foram submetidas ao corte ao atingirem entre 25 e $30 \mathrm{~cm}$ de altura. Neste ponto foram coletadas as amostras e, posteriormente, a área total da parcela foi cortada simulando o pastejo, buscando-se manter a altura de resteva entre 7 e $10 \mathrm{~cm}$, permitindo o rebrote. Este procedimento foi repetido novamente quando as espécies atingiam a altura indicada até que as plantas apresentassem o primeiro nó, que corresponde ao meristema apical, na altura de $10 \mathrm{~cm}$, aproximadamente. A partir desta condição, foi realizado o diferimento, permitindo-se o desenvolvimento final das culturas.

A massa de forragem inicial foi estimada por meio de cinco subamostras por parcela, cortadas rente ao solo, utilizando-se a média destas como valor de referência. A área de corte tinha forma retangular, com dimensões de $50 \times 30 \mathrm{~cm}$. As áreas cortadas para determinação da massa de forragem foram excluídas, não sendo mais avaliadas. Após a retirada das amostras, em cada avaliação, fez-se o corte entre 7 e $10 \mathrm{~cm}$ de altura para, uniformização da parcela, com o objetivo de simular o pastejo. Após este procedimento, foi determinada a massa de forragem residual, à semelhança da massa de forragem inicial. A forragem das amostras cortadas foi homogeneizada, sendo retirada uma subamostra para determinação das composições botânica e estrutural das espécies avaliadas, fazendo-se a separação da lâmina foliar, colmo+bainha e material senescente. Esses componentes foram secos em estufa de ar forçado a $55^{\circ} \mathrm{C}$ até peso constante, para determinação dos teores de matéria parcialmente seca, calculando-se, a seguir, a massa de cada componente.

Para o cálculo de acúmulo de forragem, foi feita a subtração da massa de forragem inicial pela massa de forragem residual do corte anterior. O acúmulo de forragem da emergência até o primeiro corte foi considerado igual à massa de forragem desse corte. A taxa de acúmulo diário foi determinada dividindo-se o acúmulo de forragem pelo número de dias entre um corte e outro. Também foi determinada a taxa de acúmulo de lâminas foliares. Para a colheita de grãos, foram coletadas em cada parcela cinco amostras com a mesma área de corte utilizada para determinação da massa de forragem. Foram avaliados o peso do hectolitro, o peso de mil grãos e o rendimento de grãos ajustado para umidade padrão de $13 \%$.

O delineamento experimental utilizado foi o inteiramente casualizado, com 12 tratamentos (genótipos), três repetições (parcelas), com medidas repetidas no tempo (cortes). Os resultados foram submetidos à análise de variância e as médias comparadas entre si pelo teste de Tukey a 5\% de 
probabilidade do erro. O teste de contrastes (teste " $\mathrm{t}$ " de Student) foi utilizado para comparar as espécies.

\section{Resultados e Discussão}

No decorrer do período de avaliação, foram realizados três cortes (Tabelas 1 e 2), com intervalos variando entre 16 e 38 dias. Os genótipos mais precoces para produção de forragem foram o triticale BRS 148, o centeio BR1 e a cevada BRS Marciana. O primeiro corte foi realizado nos dia $20 \mathrm{e}$ 22/05, 40 e 42 dias após a semeadura. A precocidade deste genótipo de centeio também foi relatada por Noro et al. (2003), que, na região do Planalto Médio do Rio Grande do Sul, observaram altura de $30 \mathrm{~cm}$ e massa de forragem de $2.026 \mathrm{~kg} / \mathrm{ha}$ de MS após 47 dias da semeadura. Ressaltando esta característica, Roso et al. (2000) verificaram, na mesma região onde foi realizado este trabalho, que o centeio BR 1 e o triticale CEP 23 participaram com 91,5\% e 75,3\% da massa de forragem nos primeiros 40 dias de avaliação quando consorciados com azevém em pastejo com bovinos de corte. Os genótipos mais tardios foram os trigos BRS Tarumã, BRS Guatambu e BRS 277, com o primeiro corte realizado 72 dias após a semeadura, entre os dias 19 e 21/06.

A altura das plantas ao corte (Tabela1) não diferiu entre os genótipos e manteve-se dentro do intervalo proposto na metodologia. Esta similaridade, no entanto, não foi observada na massa de forragem, que diferiu $(\mathrm{P}<0,05)$ entre os três cortes realizados e na média. O genótipo com valores mais elevados foram os trigos BRS Tarumã e BRS Guatambu. De maneira geral, os genótipos mais tardios foram os que apresentaram massa de forragem mais elevada, o que possivelmente se deve ao maior perfilhamento das espécies tardias em relação às espécies precoces. Comparando-se as espécies, os trigos apresentaram massa de forragem inicial e residual superiores aos das demais espécies.

Para a aveia-preta, a massa de forragem foi similar entre os genótipos, com produção intermediária entre os genótipos de triticale e cevada e os de trigo. No centeio BRS Serrano, a massa de forragem foi similar à das aveias, porém superior à do BR 1, provavelmente devido ao maior perfilhamento, característica marcante deste genótipo (Fontaneli et al., 2007). Na massa de forragem residual (Tabela 1), foram observadas diferenças nos dois primeiros cortes e na média. Alguns genótipos, principalmente o centeio BRS Serrano e a aveia-preta Comum, apresentaram substancial redução da massa de forragem residual entre o primeiro e o segundo corte, fato possivelmente decorrente da perda de plantas com a remoção do meristema apical, ocorrido no primeiro corte, e pode indicar maior sensibilidade destes materiais à desfolha. Scheffer-Basso et al. (2001),

Tabela 1 - Massa de forragem (kg de MS/ha) inicial e residual em genótipos de espécies de cereais de inverno de duplo propósito

\begin{tabular}{|c|c|c|c|c|c|c|c|}
\hline \multirow[t]{2}{*}{ Espécie } & \multirow[t]{2}{*}{ Genótipo } & \multirow[t]{2}{*}{ Altura (cm) } & \multicolumn{3}{|c|}{ Cortes } & \multirow[t]{2}{*}{ Média } & \multirow[t]{2}{*}{ CV (\%) } \\
\hline & & & 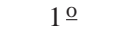 & $2 \underline{0}$ & $3 \underline{0}$ & & \\
\hline \multicolumn{8}{|c|}{ Massa de forragem inicial } \\
\hline Triticale & BRS 148 & $28,9 a$ & $1397 \mathrm{~cd}$ & 1709cd & $2462 \mathrm{bc}$ & $1856 f g$ & \multirow[t]{12}{*}{9,21} \\
\hline Cevada & BRS Marciana & $27,6 a$ & $1426 \mathrm{~cd}$ & $1701 \mathrm{~cd}$ & $2430 \mathrm{bc}$ & $1853 \mathrm{fg}$ & \\
\hline \multirow[t]{2}{*}{ Centeio } & BR 1 & $27,8 \mathrm{a}$ & 1229d & $1536 d$ & $2175 c$ & $1646 g$ & \\
\hline & BRS Serrano & $27,8 a$ & 1686bcd & $2775 b$ & $2411 \mathrm{bc}$ & 2291cd & \\
\hline Aveia-branca & UPF 18 & $27,9 a$ & $1360 \mathrm{~cd}$ & $1825 \mathrm{~cd}$ & $2646 \mathrm{bc}$ & 1944defg & \\
\hline \multirow[t]{3}{*}{ Aveia-preta } & UPFA 21 - Moreninha & $28,7 \mathrm{a}$ & $1700 \mathrm{bcd}$ & 2128bcd & 3633bc & 2154def & \\
\hline & Agro-zebu & 28,8 a & $1756 b c d$ & $2260 \mathrm{bc}$ & 2873ab & $2296 \mathrm{~cd}$ & \\
\hline & Comum & $28,2 \mathrm{a}$ & 1746 bcd & $2242 \mathrm{bc}$ & $2715 \mathrm{bc}$ & 2234 cde & \\
\hline \multirow[t]{5}{*}{ Trigo } & BRS 277 & $27,8 \mathrm{a}$ & 2039ab & $3656 a$ & $2650 \mathrm{bc}$ & 2559bc & \\
\hline & BRS Guatambu & $28,7 a$ & $2327 a$ & $2636 b$ & $2715 \mathrm{bc}$ & $2782 \mathrm{ab}$ & \\
\hline & BRS Tarumã & $27,8 \mathrm{a}$ & $2103 a b$ & $3728 a$ & $3375 a$ & 3069a & \\
\hline & BRS Umbu & 29,3 a & 1891abc & $1956 \mathrm{~cd}$ & $2765 b c$ & 2174def & \\
\hline & \multicolumn{7}{|c|}{ Massa de forragem residual } \\
\hline Triticale & BRS 148 & $9,5 a$ & $591 d$ & 793ab & $1404 \mathrm{a}$ & 929de & 13,06 \\
\hline Cevada & BRS Marciana & $9,2 \mathrm{a}$ & $544 d$ & $884 b c$ & $1513 a$ & 980 cde & \\
\hline \multirow[t]{2}{*}{ Centeio } & BR 1 & $9,6 a$ & $599 d$ & $770 \mathrm{c}$ & $1194 a$ & $854 \mathrm{e}$ & \\
\hline & BRS Serrano & $9,7 \mathrm{a}$ & $1039 a b$ & $841 b c$ & $1645 a$ & $1175 b c$ & \\
\hline Aveia-branca & UPF 18 & $9,5 a$ & 549d & $680 \mathrm{c}$ & $1269 a$ & 833e & \\
\hline \multirow[t]{3}{*}{ Aveia-preta } & UPFA 21 - Moreninha & $9,4 \mathrm{a}$ & 827bcd & 919bc & $1294 \mathrm{a}$ & 1014 cde & \\
\hline & Agro-zebu & $9,3 a$ & 707cd & $1001 \mathrm{bc}$ & $1256 a$ & $988 c$ de & \\
\hline & Comum & $9,2 \mathrm{a}$ & 1000 abc & $763 c$ & $1370 \mathrm{a}$ & 1045bcde & \\
\hline \multirow[t]{4}{*}{ Trigo } & BRS 277 & $9,5 a$ & $1125 a b$ & $1940 \mathrm{a}$ & 1599a & 1152bcd & \\
\hline & BRS Guatambu & $9,4 \mathrm{a}$ & $1203 a$ & $1171 b$ & $1405 a$ & 1260b & \\
\hline & BRS Tarumã & $9,6 a$ & $1200 \mathrm{a}$ & $1696 a$ & $1592 \mathrm{a}$ & $1500 a$ & \\
\hline & BRS Umbu & $9,6 \mathrm{a}$ & $1075 \mathrm{ab}$ & $974 \mathrm{bc}$ & $1395 a$ & 1148bcd & \\
\hline
\end{tabular}

Médias seguidas por letras distintas na coluna diferem entre si pelo teste Tukey a 5\% de probabilidade. 
trabalhando com 21 genótipos de aveia, observaram maior redução no número de perfilhos entre o primeiro e o segundo cortes para a aveia-preta Comum. Em contrapartida, os trigos BRS Tarumã e BRS 277 tiveram comportamento inverso, com aumento da massa de forragem residual neste período, devido ao maior perfilhamento (Mcrae, 2003). No terceiro corte, os genótipos não apresentaram diferenças significativas $(\mathrm{P}<0,05)$ e os valores de massa de forragem residual foram de $1.194 \mathrm{~kg} / \mathrm{ha}$ (Cevada BR 1) até $1.695 \mathrm{~kg} / \mathrm{ha}$ (centeio BRS Serrano).

Para a produção de forragem e de biomassa de lâminas foliares (Tabela 2), observou-se distribuição distinta entre

Tabela 2 - Produção e taxa de acúmulo de forragem e de biomassa de lâminas foliares em genótipos de espécies de cereais de inverno de duplo propósito

\begin{tabular}{|c|c|c|c|c|c|c|c|c|c|c|}
\hline \multirow[t]{2}{*}{ Espécie } & \multirow[t]{2}{*}{ Genótipo } & \multicolumn{2}{|c|}{ 1ㅇ corte } & \multicolumn{2}{|c|}{ 2으 corte } & \multicolumn{2}{|c|}{ 3ㅇ corte } & \multicolumn{2}{|c|}{ Total/média } & \multirow[t]{2}{*}{ CV (\%) } \\
\hline & & Dias & $\mathrm{kg} / \mathrm{ha}$ & Dias & $\mathrm{kg} / \mathrm{ha}$ & Dias & $\mathrm{kg} / \mathrm{ha}$ & Dias & $\mathrm{kg} / \mathrm{ha}$ & \\
\hline & \multicolumn{10}{|c|}{ Produção de forragem (kg/ha de MS) } \\
\hline Triticale & BRS 148 & 40 & $1397 \mathrm{~cd}$ & 22 & $1118 \mathrm{bc}$ & 22 & 1683a & 84 & 4199 cde & 7,14 \\
\hline Cevada & BRS Marciana & 42 & $1426 \mathrm{~cd}$ & 22 & $1157 \mathrm{bc}$ & 30 & $1546 \mathrm{ab}$ & 94 & 4130de & \\
\hline \multirow[t]{2}{*}{ Centeio } & BR 1 & 40 & 1229d & 22 & $936 \mathrm{c}$ & 22 & $1405 \mathrm{ab}$ & 84 & 3570 e & \\
\hline & BRS Serrano & 57 & 1686bcd & 34 & $1736 b$ & 38 & $1569 a b$ & 119 & 4992abcd & \\
\hline Aveia-branca & UPF 18 & 53 & $1360 \mathrm{~cd}$ & 28 & $1275 b c$ & 23 & $1965 a$ & 104 & 4602bcd & \\
\hline \multirow[t]{3}{*}{ Aveia-preta } & UPFA 21 - Moreninha & 55 & 1700 bcd & 22 & $1301 \mathrm{bc}$ & 31 & $1713 \mathrm{ab}$ & 108 & 4715bcd & \\
\hline & Agro-zebu & 55 & 1756bcd & 23 & $1553 b c$ & 30 & $1872 \mathrm{a}$ & 108 & $5182 \mathrm{abc}$ & \\
\hline & Comum & 54 & $1746 \mathrm{bcd}$ & 24 & $1242 b c$ & 32 & $1951 \mathrm{a}$ & 110 & 4940abcd & \\
\hline \multirow[t]{5}{*}{ Trigo } & BRS 277 & 72 & 2039ab & 22 & 2531a & 28 & $711 \mathrm{c}$ & 122 & $5282 \mathrm{ab}$ & \\
\hline & BRS Guatambu & 70 & $2327 \mathrm{a}$ & 23 & $1432 \mathrm{bc}$ & 28 & $1543 \mathrm{ab}$ & 122 & $5303 \mathrm{ab}$ & \\
\hline & BRS Tarumã & 70 & $2103 a b$ & 23 & $2522 \mathrm{a}$ & 34 & $1679 a b$ & 127 & $5888 \mathrm{a}$ & \\
\hline & BRS Umbu & 60 & $1891 \mathrm{abc}$ & 16 & $880 \mathrm{c}$ & 28 & $1816 \mathrm{a}$ & 104 & 4499bcde & \\
\hline & \multicolumn{10}{|c|}{ Produção de biomassa de lâminas foliares (kg/ha de MS) } \\
\hline Triticale & BRS 148 & 40 & $724 \mathrm{ef}$ & 22 & 411d & 22 & 518bc & 84 & $1181 \mathrm{c}$ & 12,20 \\
\hline Cevada & BRS Marciana & 42 & $662 \mathrm{f}$ & 22 & 572 bcd & 30 & $677 \mathrm{ab}$ & 92 & $1423 b c$ & \\
\hline \multirow[t]{2}{*}{ Centeio } & BR 1 & 40 & 668ef & 22 & $455 \mathrm{~cd}$ & 22 & 488bc & 84 & $1170 \mathrm{c}$ & \\
\hline & BRS Serrano & 57 & $1039 c d$ & 34 & $802 b c$ & 38 & $642 \mathrm{abc}$ & 119 & $1855 b$ & \\
\hline Aveia-branca & UPF 18 & 53 & 805def & 28 & 754bcd & 23 & $866 a$ & 104 & $1837 b$ & \\
\hline \multirow[t]{3}{*}{ Aveia-preta } & UPFA 21 - Moreninha & 55 & 945 cde & 22 & $631 \mathrm{bcd}$ & 31 & 748ab & 108 & $1727 \mathrm{bc}$ & \\
\hline & Agro-zebu & 55 & 942 cde & 23 & 711 bcd & 30 & $714 \mathrm{ab}$ & 108 & $1672 \mathrm{bc}$ & \\
\hline & Comum & 54 & 941 cde & 24 & 713bcd & 32 & 613abc & 110 & $1616 \mathrm{bc}$ & \\
\hline \multirow[t]{5}{*}{ Trigo } & BRS 277 & 72 & 1339ab & 22 & 825b & 28 & 331c & 122 & $1715 b c$ & \\
\hline & BRS Guatambu & 70 & 1459a & 23 & 595bcd & 28 & 776ab & 122 & $1946 a b$ & \\
\hline & BRS Tarumã & 70 & $1340 \mathrm{ab}$ & 23 & 1461a & 34 & 640 abc & 127 & $2512 \mathrm{a}$ & \\
\hline & BRS Umbu & 60 & 1091bc & 16 & 535bcd & 28 & $601 \mathrm{abc}$ & 104 & $1509 b c$ & \\
\hline & \multicolumn{10}{|c|}{ Taxa de acúmulo diário de forragem (kg/ha/dia de MS) } \\
\hline Triticale & BRS 148 & 28 & 34,93a & 22 & $50,81 b$ & 22 & $76,53 \mathrm{a}$ & 84 & $54,09 a b$ & 14,88 \\
\hline Cevada & BRS Marciana & 31 & $35,66 a$ & 22 & $52,59 b$ & 30 & $51,56 \mathrm{bc}$ & 92 & $46,60 \mathrm{~b}$ & \\
\hline \multirow[t]{2}{*}{ Centeio } & BR 1 & 28 & $30,72 \mathrm{ab}$ & 22 & $42,58 b$ & 22 & $63,86 a b c$ & 84 & $45,72 b$ & \\
\hline & BRS Serrano & 40 & $29,58 a b$ & 34 & $72,34 b$ & 38 & $41,30 \mathrm{~cd}$ & 119 & $47,74 b$ & \\
\hline Aveia-branca & UPF 18 & 35 & $25,66 b$ & 28 & $55,46 b$ & 23 & $70,20 \mathrm{ab}$ & 104 & $50,44 b$ & \\
\hline Aveia-preta & UPFA 21 - Moreninha & 36 & $30,91 \mathrm{ab}$ & 22 & $59,13 b$ & 31 & $55,27 \mathrm{abc}$ & 108 & $48,44 b$ & \\
\hline & Agro-zebu & 36 & $31,94 \mathrm{ab}$ & 23 & $67,52 b$ & 30 & $62,41 \mathrm{abc}$ & 108 & $53,96 a b$ & \\
\hline & Comum & 37 & $32,34 \mathrm{ab}$ & 24 & $51,76 b$ & 32 & $60,97 \mathrm{abc}$ & 110 & $48,35 b$ & \\
\hline Trigo & BRS 277 & 41 & $28,32 \mathrm{ab}$ & 22 & $115,0 \mathrm{a}$ & 28 & $25,40 \mathrm{ab}$ & 122 & $56,26 a b$ & \\
\hline & BRS Guatambu & 41 & $33,24 a b$ & 23 & $62,27 b$ & 28 & $53,23 \mathrm{bc}$ & 122 & $49,58 b$ & \\
\hline & BRS Tarumã & 42 & $30,05 a b$ & 23 & $109,6 a$ & 34 & $49,38 \mathrm{bc}$ & 127 & $63,04 \mathrm{a}$ & \\
\hline & BRS Umbu & 35 & $30,02 \mathrm{ab}$ & 16 & $55,05 b$ & 28 & $64,87 \mathrm{ab}$ & 104 & $49,98 b$ & \\
\hline & & Taxa & e acúmulo & ́rio de & âminas fol & s $(\mathrm{kg} /$ & 1/und ue ins & & & \\
\hline Triticale & BRS 148 & 28 & $18,11 \mathrm{ab}$ & 22 & $18,71 \mathrm{c}$ & 22 & $23,55 a b$ & 84 & $20,12 b c$ & 16,42 \\
\hline Cevada & BRS Marciana & 31 & $16,56 \mathrm{ab}$ & 22 & $26,00 \mathrm{bc}$ & 30 & $22,59 \mathrm{abc}$ & 92 & $21,72 \mathrm{bc}$ & \\
\hline Centeio & BR 1 & 28 & $16,07 \mathrm{ab}$ & 22 & $20,72 c$ & 22 & $22,18 \mathrm{abc}$ & 84 & $19,86 \mathrm{c}$ & \\
\hline & BRS Serrano & 40 & $18,23 a b$ & 34 & $33,44 \mathrm{bc}$ & 38 & $16,90 \mathrm{bc}$ & 119 & $22,86 \mathrm{bc}$ & \\
\hline Aveia-branca & UPF 18 & 35 & $15,19 b$ & 28 & $32,80 \mathrm{bc}$ & 23 & $30,94 a$ & 104 & $26,31 b$ & \\
\hline Aveia-preta & UPFA 21 - Moreninha & 36 & $17,18 \mathrm{ab}$ & 22 & $28,68 \mathrm{bc}$ & 31 & $24,14 \mathrm{ab}$ & 108 & $23,34 \mathrm{bc}$ & \\
\hline & Agro-zebu & 36 & $17,13 a b$ & 23 & $30,94 b c$ & 30 & $23,83 a b$ & 108 & $23,97 b c$ & \\
\hline & Comum & 37 & $17,12 \mathrm{ab}$ & 24 & $29,72 b c$ & 32 & $19,17 \mathrm{bc}$ & 110 & $22,01 \mathrm{bc}$ & \\
\hline Trigo & BRS 277 & 41 & $19,13 a b$ & 22 & $37,49 b$ & 28 & $11,85 \mathrm{c}$ & 122 & $22,82 b c$ & \\
\hline & BRS Guatambu & 41 & $20,85 a$ & 23 & $25,89 \mathrm{bc}$ & 28 & $26,76 a b$ & 122 & $24,50 \mathrm{bc}$ & \\
\hline & BRS Tarumã & 42 & $19,14 \mathrm{ab}$ & 23 & $63,55 a$ & 34 & 18,82 bc & 127 & $33,84 a$ & \\
\hline & BRS Umbu & 35 & $18,19 a b$ & 16 & $33,45 b c$ & 28 & $21,47 a b c$ & 104 & $24,37 \mathrm{bc}$ & \\
\hline
\end{tabular}

Médias seguidas por letras distintas, na coluna, diferem entre si pelo teste Tukey a 5\% de probabilidade. 
os genótipos no decorrer dos cortes. O genótipo mais produtivo para estas características foram os trigos BRS Tarumã e BRS Guatambu. O trigo BRS Tarumã e a aveiabranca UPF 18 produziram, respectivamente, $42 \%$ e $40 \%$ da massa de forragem na forma de lâminas foliares. Esta característica é altamente desejável em uma forrageira, uma vez que as folhas verdes são a fração mais nutritiva das plantas, permitindo melhor desempenho dos animais (Muehlmann et al., 1997). Já o triticale BRS 148 produziu apenas $28 \%$ da forragem sob forma de lâminas foliares, em decorrência da precoce maturidade reprodutiva e do alongamento dos colmos desta espécie (Ferolla et al., 2007).

Em comparação à primeira avaliação, com a sucessão dos cortes, os genótipos de trigo tenderam a reduzir sua produção de biomassa de lâminas foliares. Nesta abordagem, a aveia-branca UPF 18 foi o genótipo que apresentou maior estabilidade entre os cortes, com produção total inferior ao BRS Tarumã, mas similar aos demais genótipos de trigo. Em comparação aos genótipos de aveia-preta Agro Zebu, UPFA 21- Moreninha e Comum, a produção de lâminas foliares da aveia-branca foi semelhante. Rendimento inferior ao observado neste trabalho foi relatado por Scheffer-Basso et al. (2001), que obtiveram, para o mesmo genótipo em quatro cortes, produção de forragem de $3.753 \mathrm{~kg} / \mathrm{ha}$ de MS, semelhante ao observado por Bortolini et al. (2004) no genótipo UPF 15 em dois cortes.

Não foi observado efeito de genótipo sobre a produção de forragem e de lâminas foliares da aveia-preta. Os rendimentos observados foram inferiores aos relatados por Noro et al. (2003), de 5.280 e $7.230 \mathrm{~kg} / \mathrm{ha} \mathrm{de} \mathrm{MS} \mathrm{para} \mathrm{as} \mathrm{aveias}$ preta Comum e IAPAR 61, respectivamente. Cecato et al. (2001), em experimento conduzido no Paraná com vários materiais genéticos, observaram produções de 6.700 a $11.030 \mathrm{~kg} / \mathrm{ha}$ de MS. O rendimento abaixo do esperado, constatado entre os genótipos de aveia-preta, pode ser atribuído, em parte, à maior suscetibilidade destes materiais à ferrugem da folha (Puccinia coronata sp. avenae), sobretudo a aveia-comum, que apresentou os primeiros focos. Em anos favoráveis a este patógeno, podem ocorrer perdas superiores a $50 \%$ no rendimento de forragem e grãos (Martinelli et al., 1994).

Para a taxa de acúmulo de forragem e de lâminas foliares, o comportamento foi similar ao da produção de forragem, com valores médios mais elevados para os trigos BRS Tarumã, BRS 277, para a aveia Agro Zebu e para o triticale BRS 148. Ressalta-se que, no primeiro corte, a taxa de acúmulo de forragem e de lâminas foliares foi similar entre os genótipos, com menores valores para a aveia UPF 18. No corte subsequente, os valores foram maiores para os trigos
BRS 277 e BRS Tarumã e apresentaram, no entanto, expressiva redução do segundo para o terceiro corte, comportamento que pode ser atribuído à redução na taxa de fotossíntese e à alteração na alocação relativa de fotoassimilados, provocada pela intensa desfolhação (Parsons et al., 1988). Para a taxa de acúmulo de lâminas foliares, o melhor resultado, na média dos três cortes, foi obtido com o trigo BRS Tarumã.

$\mathrm{Na}$ análise da composição estrutural dos genótipos (Tabela 3), verificou-se maior participação de lâminas foliares nos cortes iniciais, sobretudo para os trigos. Considerando-se os valores médios, as aveias e o centeio BRS Serrano apresentaram resultado intermediário e as menores participações de lâminas foliares foram obtidas com os genótipos de triticale, de cevada e o centeio BR 1.

A participação do material senescente foi maior nos genótipos que apresentaram valores mais elevados de massa de forragem, como os trigos BRS 277, BRS Tarumã e a aveia Agro Zebu. Essa condição provavelmente dificultou a penetração de luz no dossel, aumentando o sombreamento do estrato inferior das plantas e contribuindo para o aumento da senescência. As exceções a esta tendência foram o triticale e a cevada, que também apresentaram elevada participação de material senescente, apesar de terem valores mais baixos de massa de forragem, que pode ser atribuído ao alongamento precoce dos entrenós, ocasionando perda de plantas pela remoção do meristema apical, em decorrência da desfolha (Roso et al., 2000).

A presença de outras espécies variou entre as espécies e os genótipos testados. Essa variação pode ser atribuída a diversos fatores, entre eles, a velocidade de cobertura do solo após a semeadura, o perfilhamento e a alelopatia de algumas espécies.

A presença de outras espécies variou entre as espécies e os genótipos testados e esta variação pode estar relacionada a diversos fatores, como a velocidade de cobertura do solo após a semeadura, o perfilhamento e a alelopatia de algumas espécies. Os tratamentos formados pelos genótipos de centeio foram os que apresentaram menor participação de outras espécies, confirmando o efeito alelopático deste cereal (Rice, 1984). O trigo BRS Umbu e o triticale BRS 148 também tiveram menores participações de outras espécies, provavelmente devido à arquitetura do dossel, elevada participação de folhas e ao ângulo formado por elas, que permitiu rápida cobertura do solo após a emergência. As outras espécies foram compostas principalmente por roseta (Soliva pterosperma), cevadilha (Bromus auleticus Trinius), guanxuma (Sida sp.) e azevém. 
A maior participação de lâminas foliares na massa de forragem residual (Tabela 4) foi obtida nos genótipos de trigo. Essa participação, juntamente com a relação lâmina foliar/colmo do resíduo (Tabela 5), pode explicar a maior taxa de acúmulo de forragem destes materiais. Segundo
Gomide \& Zago (1980), a recuperação das plantas após a desfolha é influenciada pela área foliar remanescente. O genótipo BRS Tarumã, que apresentou a maior taxa de acúmulo de forragem e de lâminas foliares, também foi o genótipo que apresentou maior participação de lâminas

Tabela 3 - Componentes botânicos e estruturais (kg/ha de MS) da massa de forragem de genótipos de espécies de cereais de inverno de duplo propósito submetidos ao corte

\begin{tabular}{|c|c|c|c|c|c|c|c|}
\hline \multirow[t]{2}{*}{ Espécie } & \multirow[t]{2}{*}{ Genótipo } & \multirow[t]{2}{*}{ Altura média } & \multicolumn{3}{|c|}{ Corte } & \multirow[t]{2}{*}{ Média } & \multirow[t]{2}{*}{ CV (\%) } \\
\hline & & & 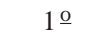 & $2 \underline{0}$ & 30 & & \\
\hline & & \multicolumn{6}{|c|}{ Lâminas foliares } \\
\hline Triticale & BRS 148 & $28,9 a$ & 724 ef & $663 d$ & $771 \mathrm{bc}$ & $719 \mathrm{f}$ & 11,35 \\
\hline Cevada & BRS Marciana & $27,6 a$ & $662 \mathrm{f}$ & $745 d$ & 907 abc & $772 \mathrm{ef}$ & \\
\hline \multirow[t]{2}{*}{ Centeio } & BR 1 & $27,8 \mathrm{a}$ & $668 \mathrm{ef}$ & $681 d$ & $711 \mathrm{c}$ & $687 \mathrm{f}$ & \\
\hline & BRS Serrano & $27,8 \mathrm{a}$ & $1039 c d$ & $1212 \mathrm{bc}$ & 813abc & $1022 \mathrm{~cd}$ & \\
\hline Aveia-branca & UPF 18 & $27,9 \mathrm{a}$ & 805def & 971cd & $1081 \mathrm{a}$ & 952d & \\
\hline \multirow{3}{*}{ Aveia-preta } & UPFA 21 - Moreninha & 28,7 a & 945 cde & $978 c d$ & $960 \mathrm{abc}$ & $961 \mathrm{~cd}$ & \\
\hline & Agro-zebu & $28,8 a$ & 942 cde & $958 \mathrm{~cd}$ & $944 \mathrm{abc}$ & 948de & \\
\hline & Comum & $28,2 \mathrm{a}$ & 941 cde & $1002 \mathrm{bcd}$ & 777abc & 907de & \\
\hline \multirow[t]{5}{*}{ Trigo } & BRS 277 & $27,8 a$ & $1339 a b$ & 1383b & $690 c$ & $1137 \mathrm{bc}$ & \\
\hline & BRS Guatambu & 28,7 a & $1459 a$ & $1170 \mathrm{bc}$ & 988abc & $1206 b$ & \\
\hline & BRS Tarumã & $27,8 a$ & $1340 \mathrm{ab}$ & 1871a & $1075 \mathrm{ab}$ & $1429 a$ & \\
\hline & BRS Umbu & $29,3 a$ & $1091 b c$ & $908 c d$ & $843 a b c$ & 947 de & \\
\hline & & \multicolumn{6}{|c|}{ Colmo + bainha } \\
\hline Triticale & BRS 148 & $28,9 a$ & $414 \mathrm{ab}$ & 661bcd & $1033 \mathrm{~cd}$ & 703bcdef & 13,53 \\
\hline Cevada & BRS Marciana & $27,6 a$ & $432 \mathrm{ab}$ & 532d & $831,4 d$ & 598ef & \\
\hline \multirow[t]{2}{*}{ Centeio } & BR 1 & $27,8 a$ & 373ab & $560 d$ & 907cd & 613def & \\
\hline & BRS Serrano & $27,8 \mathrm{a}$ & $410 \mathrm{ab}$ & $947 \mathrm{ab}$ & 1097bcd & $818 \mathrm{abc}$ & \\
\hline Aveia-branca & UPF 18 & $27,9 a$ & 315b & 486d & 854d & $552 \mathrm{f}$ & \\
\hline \multirow[t]{3}{*}{ Aveia-preta } & UPFA 21 - Moreninha & $28,7 a$ & 449ab & $624 c d$ & $1000 \mathrm{~cd}$ & 691cdef & \\
\hline & Agro-zebu & $28,8 \mathrm{a}$ & $529 a$ & 700bcd & $1026 \mathrm{~cd}$ & 752bcdef & \\
\hline & Comum & $28,2 \mathrm{a}$ & 424ab & 706bcd & $1136 b c d$ & 775abcd & \\
\hline \multirow[t]{5}{*}{ Trigo } & BRS 277 & $27,8 \mathrm{a}$ & $377 \mathrm{ab}$ & $1152 \mathrm{a}$ & $1245 a b c$ & $925 a$ & \\
\hline & BRS Guatambu & 28,7 a & 459ab & $862 \mathrm{abc}$ & $1243 a b c$ & $855 a b$ & \\
\hline & BRS Tarumã & $27,8 \mathrm{a}$ & 329b & $862 \mathrm{abc}$ & $1595 a$ & $928 a$ & \\
\hline & BRS Umbu & $29,3 \mathrm{a}$ & $461 \mathrm{ab}$ & $644 c d$ & $1468 \mathrm{ab}$ & 858ab & \\
\hline & & \multicolumn{6}{|c|}{ Material senescente } \\
\hline Triticale & BRS 148 & $28,9 a$ & $118 \mathrm{ab}$ & 181bc & 332ab & $210 \mathrm{~cd}$ & 23,13 \\
\hline Cevada & BRS Marciana & $27,6 \mathrm{a}$ & $155 a b$ & 204bc & 239b & $199 c d$ & \\
\hline \multirow[t]{2}{*}{ Centeio } & BR 1 & $27,8 \mathrm{a}$ & $90 \mathrm{~b}$ & $141 \mathrm{c}$ & 290b & $174 d$ & \\
\hline & BRS Serrano & $27,8 \mathrm{a}$ & $114 \mathrm{ab}$ & 291bc & $241 b$ & $227 \mathrm{~cd}$ & \\
\hline Aveia-branca & UPF 18 & $27,9 a$ & $128 \mathrm{ab}$ & $187 \mathrm{bc}$ & $420 \mathrm{ab}$ & 245bcd & \\
\hline \multirow[t]{3}{*}{ Aveia-preta } & UPFA 21 - Moreninha & $28,7 a$ & $145 \mathrm{ab}$ & 270bc & $320 a b$ & 245bcd & \\
\hline & Agro-zebu & $28,8 a$ & 139ab & 326b & $502 \mathrm{a}$ & 323ab & \\
\hline & Comum & $28,2 \mathrm{a}$ & $168 \mathrm{ab}$ & $252 b c$ & 419ab & $280 \mathrm{bc}$ & \\
\hline \multirow[t]{5}{*}{ Trigo } & BRS 277 & $27,8 \mathrm{a}$ & $135 \mathrm{ab}$ & $572 \mathrm{a}$ & 277b & 328ab & \\
\hline & BRS Guatambu & $28,7 a$ & 198ab & $322 b$ & 270b & 264bcd & \\
\hline & BRS Tarumã & $27,8 \mathrm{a}$ & 243a & $590 a$ & $305 a b$ & 379a & \\
\hline & BRS Umbu & $29,3 \mathrm{a}$ & $125 \mathrm{ab}$ & $211 \mathrm{bc}$ & $241 b$ & $193 \mathrm{~cd}$ & \\
\hline & & & & tras espé & & & \\
\hline Triticale & BRS 148 & $28,9 a$ & $140 \mathrm{ab}$ & 203cd & $324 \mathrm{ab}$ & 222 cde & 21,13 \\
\hline Cevada & BRS Marciana & $27,6 a$ & $176 a b$ & $218 \mathrm{~cd}$ & $452 \mathrm{a}$ & 282bc & \\
\hline Centeio & BR 1 & $27,8 \mathrm{a}$ & $96 b$ & $152 d$ & $166 b$ & $171 \mathrm{e}$ & \\
\hline & BRS Serrano & $27,8 \mathrm{a}$ & $122 \mathrm{ab}$ & $325 b c$ & $221 b$ & 222 cde & \\
\hline Aveia-branca & UPF 18 & $27,9 a$ & $110 \mathrm{ab}$ & $180 \mathrm{~cd}$ & $290 \mathrm{ab}$ & 193de & \\
\hline Aveia-preta & UPFA 21 - Moreninha & $28,7 \mathrm{a}$ & $159 a b$ & 255bcd & $352 \mathrm{ab}$ & 255bcde & \\
\hline & Agro-zebu & $28,8 \mathrm{a}$ & $144 \mathrm{ab}$ & 275bcd & $400 \mathrm{ab}$ & 273bcd & \\
\hline & Comum & $28,2 \mathrm{a}$ & $151 \mathrm{ab}$ & 280bcd & $381 \mathrm{ab}$ & 271bcd & \\
\hline Trigo & BRS 277 & $27,8 \mathrm{a}$ & $187 \mathrm{ab}$ & 548a & $436 a$ & 391a & \\
\hline & BRS Guatambu & $28,7 a$ & $208 a$ & 281bcd & 212b & 234cde & \\
\hline & BRS Tarumã & $27,8 \mathrm{a}$ & $190 \mathrm{ab}$ & 404ab & 398ab & 331ab & \\
\hline & BRS Umbu & $29,3 a$ & $122 \mathrm{ab}$ & $192 \mathrm{~cd}$ & 210b & $175 \mathrm{e}$ & \\
\hline
\end{tabular}

Médias seguidas por letras distintas, na coluna, diferem entre si pelo teste Tukey a 5\% de probabilidade. 
foliares e maior relação lâmina foliar/colmo no resíduo de forragem. De forma análoga, os genótipos que apresentaram as menores taxas de acúmulo foram aqueles que tiveram as menores participações de lâminas foliares, como o centeio BR 1, a cevada BRS Marciana e a aveia-branca UPF 18.
A relação entre lâminas foliares e colmos da massa de forragem (Tabela 5) foi diferente entre os genótipos e as espécies estudadas. O trigo BRS Tarumã e a aveia-branca UPF 18 tiveram valores mais elevados para esta característica, apresentando, entretanto, diferenças em seu

Tabela 4 - Componentes botânicos e estruturais (kg/ha de MS) do resíduo de forragem em genótipos de espécies de cereais de inverno de duplo propósito submetidos ao corte

\begin{tabular}{|c|c|c|c|c|c|c|c|}
\hline \multirow[t]{2}{*}{ Espécie } & \multirow[t]{2}{*}{ Genótipo } & \multirow[t]{2}{*}{ Altura $(\mathrm{cm})$} & \multicolumn{3}{|c|}{ Cortes } & \multirow[t]{2}{*}{ Média } & \multirow[t]{2}{*}{$\mathrm{CV}(\%)$} \\
\hline & & & $1 \stackrel{\circ}{-}$ & $2 \underline{0}$ & $3 \underline{0}$ & & \\
\hline \multicolumn{8}{|c|}{ Lâminas foliares } \\
\hline Triticale & BRS 148 & $9,5 a$ & 251cde & 253bc & 266ab & $257 c d$ & 19,97 \\
\hline Cevada & BRS Marciana & $9,2 \mathrm{a}$ & $173 \mathrm{e}$ & $230 \mathrm{bc}$ & $264 \mathrm{ab}$ & $222 d$ & \\
\hline \multirow{2}{*}{ Centeio } & BR 1 & $9,6 a$ & 225 cde & $223 b c$ & $202 \mathrm{ab}$ & $217 d$ & \\
\hline & BRS Serrano & $9,7 a$ & $410 \mathrm{abc}$ & 171c & $269 a b$ & 283bcd & \\
\hline Aveia-branca & UPF 18 & $9,5 a$ & 216de & $214 b c$ & 199ab & 210d & \\
\hline \multirow[t]{3}{*}{ Aveia-preta } & UPFA 21 - Moreninha & $9,4 \mathrm{a}$ & 347 cde & $211 b c$ & 223ab & $261 \mathrm{~cd}$ & \\
\hline & Agro-zebu & $9,3 a$ & 245 cde & $229 b c$ & $176 b$ & $217 d$ & \\
\hline & Comum & $9,2 \mathrm{a}$ & 289 cde & $163 c$ & 233ab & $228 d$ & \\
\hline \multirow[t]{5}{*}{ Trigo } & BRS 277 & $9,5 a$ & 558ab & $358 a b$ & 193ab & $369 a b$ & \\
\hline & BRS Guatambu & $9,4 \mathrm{a}$ & $574 a$ & $212 b c$ & $192 \mathrm{ab}$ & $326 b c$ & \\
\hline & BRS Tarumã & $9,6 a$ & $555 a b$ & $435 a$ & $297 a$ & $429 a$ & \\
\hline & BRS Umbu & $9,6 \mathrm{a}$ & $372 \mathrm{bcd}$ & $242 b c$ & 223ab & $279 c d$ & \\
\hline & & \multicolumn{6}{|c|}{ Colmo + bainha } \\
\hline Triticale & BRS 148 & $9,5 a$ & 239cd & $357 c$ & $750 a$ & 449bcde & 15,68 \\
\hline Cevada & BRS Marciana & $9,2 \mathrm{a}$ & $257 c d$ & $395 c$ & $630 \mathrm{a}$ & 427 cde & \\
\hline \multirow[t]{2}{*}{ Centeio } & BR 1 & $9,6 a$ & $270 \mathrm{~cd}$ & $351 c$ & $603 a$ & 408de & \\
\hline & BRS Serrano & $9,7 \mathrm{a}$ & 412 abc & $408 c$ & $706 a$ & 509bcd & \\
\hline Aveia-branca & UPF 18 & $9,5 a$ & 224d & $270 c$ & $524 a$ & 339e & \\
\hline \multirow[t]{3}{*}{ Aveia-preta } & UPFA 21 - Moreninha & $9,4 \mathrm{a}$ & 293dc & $354 c$ & $626 a$ & 424 cde & \\
\hline & Agro-zebu & $9,3 a$ & 306bcd & $413 c$ & $573 a$ & 431cde & \\
\hline & Comum & $9,2 \mathrm{a}$ & $512 \mathrm{a}$ & $311 \mathrm{c}$ & $609 a$ & 477bcd & \\
\hline \multirow[t]{5}{*}{ Trigo } & BRS 277 & $9,5 a$ & 317bcd & $786 a$ & $794 a$ & $632 \mathrm{a}$ & \\
\hline & BRS Guatambu & $9,4 \mathrm{a}$ & 334bcd & $573 b$ & $715 \mathrm{a}$ & $541 \mathrm{abc}$ & \\
\hline & BRS Tarumã & $9,6 a$ & 348abcd & $579 b$ & $765 a$ & $564 \mathrm{ab}$ & \\
\hline & BRS Umbu & $9,6 \mathrm{a}$ & 477ab & $410 \mathrm{c}$ & $727 \mathrm{a}$ & $538 \mathrm{abc}$ & \\
\hline & & \multicolumn{6}{|c|}{ Material senescente } \\
\hline Triticale & BRS 148 & $9,5 a$ & 56de & 91c & $216 a$ & $121 \mathrm{c}$ & 22,58 \\
\hline Cevada & BRS Marciana & $9,2 \mathrm{a}$ & $52 \mathrm{e}$ & $133 \mathrm{bc}$ & $301 \mathrm{a}$ & $162 \mathrm{bc}$ & \\
\hline \multirow[t]{2}{*}{ Centeio } & BR 1 & $9,6 \mathrm{a}$ & $50 \mathrm{e}$ & $108 \mathrm{bc}$ & $207 a$ & $121 \mathrm{c}$ & \\
\hline & BRS Serrano & $9,7 \mathrm{a}$ & 112 abc & $117 \mathrm{bc}$ & $371 \mathrm{a}$ & $200 b$ & \\
\hline Aveia-branca & UPF 18 & $9,5 a$ & $52 \mathrm{e}$ & $118 \mathrm{bc}$ & $343 a$ & 171bc & \\
\hline \multirow[t]{3}{*}{ Aveia-preta } & UPFA 21 - Moreninha & $9,4 \mathrm{a}$ & 94bcde & 183bc & $255 a$ & $177 \mathrm{bc}$ & \\
\hline & Agro-zebu & $9,3 a$ & 83cde & $183 \mathrm{bc}$ & $295 a$ & $187 \mathrm{bc}$ & \\
\hline & Comum & $9,2 \mathrm{a}$ & 91bcde & $178 \mathrm{bc}$ & $259 a$ & $176 \mathrm{bc}$ & \\
\hline \multirow[t]{5}{*}{ Trigo } & BRS 277 & $9,5 a$ & 128 abc & $431 \mathrm{a}$ & $351 \mathrm{a}$ & 303a & \\
\hline & BRS Guatambu & $9,4 \mathrm{a}$ & $153 a$ & 211b & $286 a$ & $216 b$ & \\
\hline & BRS Tarumã & $9,6 a$ & $137 \mathrm{ab}$ & $460 a$ & $273 a$ & $290 a$ & \\
\hline & BRS Umbu & $9,6 \mathrm{a}$ & 107abcd & 194bc & $252 \mathrm{a}$ & 184bc & \\
\hline & & & & ras espé & & & \\
\hline Triticale & BRS 148 & $9,5 a$ & $44 \mathrm{e}$ & 89cd & $170 \mathrm{a}$ & $101 \mathrm{e}$ & 24,41 \\
\hline Cevada & BRS Marciana & $9,2 \mathrm{a}$ & 60 cde & $125 \mathrm{~cd}$ & $316 a$ & 167bcd & \\
\hline Centeio & BR 1 & $9,6 \mathrm{a}$ & 53de & $87 \mathrm{~cd}$ & $180 \mathrm{a}$ & 107de & \\
\hline & BRS Serrano & $9,7 \mathrm{a}$ & 105abcde & 144bcd & $298 a$ & $182 \mathrm{bc}$ & \\
\hline Aveia-branca & UPF 18 & $9,5 a$ & 55de & $76 \mathrm{~d}$ & $202 \mathrm{a}$ & 111de & \\
\hline Aveia-preta & UPFA 21 - Moreninha & $9,4 \mathrm{a}$ & 91bcde & $170 \mathrm{bc}$ & $189 a$ & 150 cde & \\
\hline & Agro-zebu & $9,3 \mathrm{a}$ & 71cde & $174 \mathrm{bc}$ & $210 \mathrm{a}$ & 152 cde & \\
\hline & Comum & $9,2 \mathrm{a}$ & 107abcd & $111 \mathrm{~cd}$ & $268 \mathrm{a}$ & 162bcde & \\
\hline Trigo & BRS 277 & $9,5 a$ & $121 \mathrm{abc}$ & $363 a$ & $253 a$ & $245 a$ & \\
\hline & BRS Guatambu & $9,4 \mathrm{a}$ & $142 \mathrm{ab}$ & $174 \mathrm{bc}$ & $211 \mathrm{a}$ & $176 \mathrm{bc}$ & \\
\hline & BRS Tarumã & $9,6 \mathrm{a}$ & $163 a$ & $222 b$ & $262 a$ & $216 a b$ & \\
\hline & BRS Umbu & $9,6 \mathrm{a}$ & 118abc & $126 \mathrm{~cd}$ & $192 \mathrm{a}$ & 145 cde & \\
\hline
\end{tabular}

Médias seguidas por letras distintas, na coluna, diferem entre si pelo teste Tukey a 5\% de probabilidade. 
comportamento no decorrer dos cortes. O trigo apresentou valores bastante elevados no primeiro corte, que diminuíram acentuadamente nos cortes seguintes, sobretudo no terceiro. Já a aveia-branca teve maior estabilidade nesta característica entre os cortes, à semelhança do que ocorreu com a produção de biomassa de lâminas foliares. Este comportamento é importante em plantas forrageiras utilizadas para pastejo, pois, assim como a altura do pasto, a disponibilidade de massa seca e a maior presença de folhas facilitam a apreensão de forragem pelo animal (Alden \& Whitaker, 1970).

Comportamento similar foi observado para a cevada BRS Marciana, que também apresentou relação lâmina foliar/ colmo mais estável, porém com valores médios inferiores aos da aveia-branca. Os genótipos de trigo caracterizaramse por apresentar elevada relação lâmina foliar/colmo no primeiro corte, evidenciando a menor participação de colmos neste período (Tabela 3).

Para a produção de grãos (Tabela 6), o trigo BRS Umbu apresentou maior rendimento e peso do hectolitro (PH), resultado que foi superior ao observado por Hastenpflug (2009), que, trabalhando com este genótipo no estado do Paraná, submetido ao manejo sem corte e com um e dois cortes, obteve $2.075,1.552$ e $293 \mathrm{~kg} / \mathrm{ha}$ de rendimento com PH de 77, 79 e 71 kg, respectivamente, sob condições de deficiência hídrica. No mesmo trabalho, esse autor encontrou rendimentos médios de 188 e $891 \mathrm{~kg} / \mathrm{ha}$ para os genótipos BRS Guatambu e BRS Tarumã submetidos a dois cortes, inferiores aos observados deste trabalho.

Del Duca et al. (2000), trabalhando com o genótipo de duplo propósito BRS 176, também no Paraná, observaram produtividade de $3.451,3.483$ e $2.104 \mathrm{~kg} / \mathrm{h}$ a nos tratamentos sem corte, um corte e dois cortes, respectivamente. Ressalta-se que os genótipos de trigo estudados apresentaram peso do hectolitro mais elevado, ficando acima de 78 em todos os genótipos, o que classifica o grão como do tipo 1 , segundo a Norma Brasileira de Classificação Comercialização do Trigo (Brasil, 2001).

Entre os genótipos de centeio, o BRS Serrano apresentou maior produção de grãos e menor $\mathrm{PH}$ em relação ao BR 1 . O maior rendimento pode ser atribuído ao maior número de plantas, em virtude do maior perfilhamento, e o menor $\mathrm{PH}$ pode ser explicado, em parte, pela maior participação de grãos advindos de perfilhos secundários, que apresentam menor peso se comparados aos grãos de perfilhos principais (Bortolini et al., 2004). Destaca-se, no entanto, o elevado rendimento da aveia-branca UPF 18.

Os genótipos de aveia-preta foram os que apresentaram menores valores para rendimento, $\mathrm{pH}$ e peso de mil grãos. O rendimento delas foi similar ao observado por Scheffer-

Tabela 5 - Relação folha/colmo da forragem de genótipos de espécies de cereais de inverno de duplo propósito

\begin{tabular}{|c|c|c|c|c|c|c|}
\hline \multirow[t]{2}{*}{ Espécie } & \multirow[t]{2}{*}{ Genótipo } & \multicolumn{3}{|c|}{ Corte } & \multirow[t]{2}{*}{ Média } & \multirow[t]{2}{*}{ CV (\%) } \\
\hline & & $1 \underline{0}$ & $2 \underline{0}$ & $3 \underline{0}$ & & \\
\hline & \multicolumn{6}{|c|}{ Relação lâmina foliar/colmo - massa de forragem } \\
\hline Triticale & BRS 148 & $1,75 \mathrm{c}$ & $1,00 \mathrm{c}$ & $0,74 \mathrm{~cd}$ & $1,17 \mathrm{~b}$ & 24,65 \\
\hline Cevada & BRS Marciana & $1,54 \mathrm{c}$ & $1,40 \mathrm{c}$ & $1,09 \mathrm{ab}$ & $1,34 \mathrm{~cd}$ & \\
\hline \multirow[t]{2}{*}{ Centeio } & BR 1 & $1,81 \mathrm{bc}$ & $1,21 \mathrm{c}$ & $0,79 b c d$ & $1,27 \mathrm{~cd}$ & \\
\hline & BRS Serrano & $2,57 \mathrm{bc}$ & $1,29 c$ & $0,73 \mathrm{~cd}$ & $1,53 \mathrm{bcd}$ & \\
\hline Aveia-branca & UPF 18 & $2,56 \mathrm{bc}$ & $2,07 \mathrm{ab}$ & $1,28 \mathrm{a}$ & 1,97ab & \\
\hline \multirow[t]{3}{*}{ Aveia-preta } & UPFA 21 - Moreninha & $2,09 \mathrm{bc}$ & $1,57 \mathrm{bc}$ & $0,96 \mathrm{bc}$ & $1,54 \mathrm{bcd}$ & \\
\hline & Agro-zebu & $1,79 c$ & $1,36 \mathrm{c}$ & $0,92 \mathrm{bc}$ & $1,36 \mathrm{bcd}$ & \\
\hline & Comum & $1,95 \mathrm{bc}$ & $1,42 \mathrm{c}$ & $0,70 \mathrm{~cd}$ & $1,35 \mathrm{bcd}$ & \\
\hline \multirow[t]{5}{*}{ Trigo } & BRS 277 & $3,67 a b$ & $1,21 \mathrm{c}$ & $0,55 d$ & $1,81 \mathrm{bc}$ & \\
\hline & BRS Guatambu & $3,18 \mathrm{ab}$ & $1,38 c$ & $0,80 \mathrm{bcd}$ & $1,79 b c d$ & \\
\hline & BRS Tarumã & 4,46a & $2,17 \mathrm{a}$ & $0,67 \mathrm{~cd}$ & 2,43a & \\
\hline & BRS Umbu & $2,37 \mathrm{bc}$ & $1,41 \mathrm{c}$ & $0,57 d$ & $1,45 b c d$ & \\
\hline & \multicolumn{6}{|c|}{ Relação lâmina foliar/colmo - resíduo } \\
\hline Triticale & BRS 148 & $1,05 \mathrm{bc}$ & $0,70 \mathrm{ab}$ & $0,35 \mathrm{ab}$ & $0,70 \mathrm{abc}$ & 27,29 \\
\hline Cevada & BRS Marciana & $0,67 \mathrm{C}$ & 0,58 abc & $0,43 a$ & $0,56 \mathrm{bc}$ & \\
\hline \multirow[t]{2}{*}{ Centeio } & BR 1 & $0,87 \mathrm{bc}$ & $0,63 a b c$ & $0,33 \mathrm{ab}$ & $0,61 \mathrm{bc}$ & \\
\hline & BRS Serrano & $0,98 \mathrm{bc}$ & $0,41 \mathrm{bc}$ & $0,38 \mathrm{ab}$ & $0,59 \mathrm{bc}$ & \\
\hline Aveia-branca & UPF 18 & $0,96 \mathrm{bc}$ & $0,80 \mathrm{a}$ & $0,38 \mathrm{ab}$ & $0,71 \mathrm{abc}$ & \\
\hline \multirow[t]{3}{*}{ Aveia-preta } & UPFA 21 - Moreninha & $1,19 \mathrm{bc}$ & 0,59 abc & $0,35 \mathrm{ab}$ & $0,71 \mathrm{abc}$ & \\
\hline & Agro-zebu & $0,80 \mathrm{c}$ & $0,56 a b c$ & $0,30 \mathrm{ab}$ & $0,55 \mathrm{bc}$ & \\
\hline & Comum & $0,57 \mathrm{c}$ & $0,52 \mathrm{abc}$ & $0,38 \mathrm{ab}$ & $0,49 c$ & \\
\hline \multirow[t]{4}{*}{ Trigo } & BRS 277 & $1,80 \mathrm{a}$ & $0,44 \mathrm{bc}$ & $0,24 b$ & $0,83 a b$ & \\
\hline & BRS Guatambu & $1,71 \mathrm{ab}$ & $0,37 c$ & $0,27 b$ & $0,78 \mathrm{abc}$ & \\
\hline & BRS Tarumã & 1,73a & $0,76 a$ & $0,38 \mathrm{ab}$ & $0,96 a$ & \\
\hline & BRS Umbu & $0,8 c$ & $0,56 \mathrm{abc}$ & $0,31 \mathrm{ab}$ & 0,56 bc & \\
\hline
\end{tabular}

Médias seguidas por letras distintas, na coluna, diferem entre si pelo teste Tukey a 5\% de probabilidade. 
Tabela 6 - Rendimento ajustado para a umidade padrão de 13\%, peso hectolítrico e peso de mil grãos em genótipos de espécies de cereais de inverno de duplo propósito

\begin{tabular}{|c|c|c|c|c|}
\hline Espécie & Genótipo & Rendimento ajustado (kg/ha) & Peso hectolítrico (kg) & Peso de mil grãos (g) \\
\hline Triticale & BRS 148 & $2759 b$ & $71,0 \mathrm{c}$ & $40,0 \mathrm{~b}$ \\
\hline Cevada & BRS Marciana & $2784 b$ & $66,0 \mathrm{c}$ & $48,0 \mathrm{a}$ \\
\hline Centeio & BR 1 & $1463 \mathrm{f}$ & $77,3 \mathrm{ab}$ & $20,3 \mathrm{~g}$ \\
\hline Aveia-branca & UPF 18 & $2385 c$ & $42,3 \mathrm{~d}$ & $27,0 \mathrm{f}$ \\
\hline \multirow[t]{2}{*}{ Aveia-preta } & UPFA 21 - Moreninha & $1245 f g$ & 29,3 e & $11,6 \mathrm{~h}$ \\
\hline & Agro-zebu & $1185 \mathrm{fg}$ & 31,3 e & $11,0 \mathrm{~h}$ \\
\hline \multirow{3}{*}{ Trigo } & BRS Guatambu & $2213 \mathrm{~cd}$ & $79,6 a$ & 31,3de \\
\hline & BRS Tarumã & 2767b & $81,0 \mathrm{a}$ & $33,0 \mathrm{~cd}$ \\
\hline & BRS Umbu & $3468 a$ & $82,6 a$ & $35,6 c$ \\
\hline CV (\%) & - & 4,63 & 4,16 & 4,10 \\
\hline
\end{tabular}

Médias seguidas por letras distintas, na coluna, diferem entre si pelo teste Tukey a 5\% de probabilidade.

Basso et al. (2001), que verificaram produção de $1.166 \mathrm{~kg} / \mathrm{ha}$ para a aveia-preta Comum, submetida a um corte, no Planalto Médio do Rio Grande do Sul. Na mesma região, Fontaneli \& Piovesan (1991) avaliaram genótipos de aveiapreta submetidos a dois cortes e observaram valores médios de $1.636 \mathrm{~kg} / \mathrm{ha}$.

\section{Conclusões}

Existe variabilidade entre as espécies e os genótipos de cereais de inverno avaliados para duplo propósito. Os genótipos mais indicados para produção precoce de forragem são o triticale BRS 148, o centeio BR 1 e a cevada BRS Marciana. O trigo BRS Umbu é o mais recomendado para produção de grãos. BRS Tarumã é o genótipo que apresenta resultado mais equilibrado entre produtividade de forragem e grãos, e o mais indicado para o manejo de duplo propósito na Depressão Central do Rio Grande do Sul.

\section{Referências}

ALDEN, W.G.; WHITAKER, I.A. The determinants of herbage intake by grazing sheep: the inter relationship of factors influencing herbage intake and availabity. Australian Journal of Agricultural Research, v.21, n.5, p.755-766, 1970.

BORTOLINI, P.C.; SANDINI, I.; CARVALHO, P.C.F. et al. Cereais de inverno submetidos ao corte no sistema de duplo propósito. Revista Brasileira de Zootecnia, v.33, n.1, p.45-50, 2004.

BRASIL. Ministério da Agricultura, Pecuária e Abastecimento. Instrução Normativa SARC n 7, de 15 de agosto de 2001. Regulamento técnico de identidade e de qualidade do trigo. Diário Oficial [da] República Federativa do Brasil, Brasília, DF, n. 160-E, p.33-35, 21 ago. 2001. Seção 1.

CECATO, U.; RÊGO, F.C.A.; GOMES, J.A.N. et al. Produção e composição química em cultivares e linhagens aveia (Avena spp). Acta Scientiarum, v.23, n.4, p.775-780, 2001.

COMISSÃO DE QUÍMICA E FERTILIDADE DO SOLO - RS/SC. Manual de adubação e calagem para os estados do Rio Grande do Sul e Santa Catarina. Porto Alegre: SBCS- NRS, 2004. 400p.
DEL DUCA, L.J.A.; GUARIENTI, E.M.; FONTANELI, R.S. et al. Influência de cortes simulando pastejo na composição química de grãos de cereais de inverno. Pesquisa Agropecuária Brasileira, v.34, n.9, p.1607-1614, 1999.

DEL DUCA, L.J.A.; MOLIN, R.; SANDINI, I. Experimentação de genótipos de trigo para duplo propósito na Paraná, em 1999. Passo Fundo: Embrapa Trigo, 2000. 18p. (Boletim de Pesquisa e Desenvolvimento, 6).

FEROLLA, F.S.; VÁSQUEZ, H.M.; SILVA, J.F.C. et al. Produção de matéria seca, composição da massa de forragem e relação lâmina foliar/caule + bainha de aveia-preta e triticale nos sistemas de corte e de pastejo. Revista Brasileira de Zootecnia, v.36, n.5, p.1512-1517, 2007.

FONTANELI, R.S.; FONTANELI, R.S.; DA SILVA, G. et al. Avaliação de cereais de inverno para duplo-propósito. Pesquisa Agropecuária Brasileira, v.31, n.1, p.43-50, 1996.

FONTANELI, R.S.; PIOVESAN, A.J. Efeito de cortes no rendimento de forragem e grãos de aveia. Pesquisa Agropecuária Brasileira, v.26, n.5, p.691-697, 1991.

FONTANELI, R.S.; SANTOS, H.P.; MINELLA, E. Cereais de inverno de duplo-propósito na alimentação animal: precocidade, rendimento de silagem e grãos e valor nutritivo. In: REUNIÃO NACIONAL DE PESQUISA DE CEVADA, 26., 2007, Passo Fundo. Anais... Passo Fundo: Embrapa Trigo, 2007. p.309-317.

GOMIDE, J.A.; ZAGO, C.P. Crescimento e recuperação do capim colonião após o corte. Revista Brasileira de Zootecnia, v.9, n.2, p.293-305, 1980.

HASTENPFLUG, M. Desempenho de genótipos de trigo duplopropósito sob diferentes doses de adubação nitrogenada com cortes simulando pastejo. 2009. 66f. Dissertação (Mestrado em Agronomia) - Universidade Tecnológica Federal do Paraná, Pato Branco.

MARTINELLI, J.A.; FEDERIZZI, L.C.; BENNEDETI, A.C. Redução no rendimento de grãos de aveia em função da severidade da ferrugem da folha. Summa Phytopathologica, v.40, p.116-118, 1994.

MCRAE, F. Crop agronomy and grazing management of winter cereals. NSW Agriculture, v.59, p.59-69, 2003.

MUEHLMANN, L.D.; ROCHA, M.G.; RESTLE, J. Efeito do uso exclusivo de pastagem no desenvolvimento de bezerras de corte desmamadas precocemente. Revista Brasileira de Zootecnia, v.26, n.2, p.411-415, 1997.

NORO, G.; SCHEFFER-BASSO, S.M.; FONTANELI, R.S. et al. Gramíneas anuais de inverno para produção de forragem: avaliação preliminar de cultivares. Revista Brasileira de Agrociência, v.7, n.1, p.35-40, 2003. 
PARSONS, A.J.; JOHNSON, I.R.; HARVEY, A. Use of a model to optimize the interaction between frequency and severity of intermittent defoliation and to provide a fundamental comparison of the continuous and intermittent defoliation of grass. Grass and Forage Science, v.43, n.2, p.49-59, 1988. ROCHA, M.G.; RESTLE, J.; FRIZZO, A. et al. Alternativas de utilização da pastagem hibernal para a recria de bezerras de corte. Revista Brasileira de Zootecnia, v.32, n.2, p.383-392, 2003.

RICE, E.L. Allelopathy. 2.ed. San Diego: Academic Press, 1984. $422 p$.
ROSO, C.; RESTLE, J. Aveia preta, triticale e centeio em mistura com azevém. Revista Brasileira de Zootecnia, v.29, n.1, p.85-93, 2000

SCHEFFER-BASSO, S.M.; FLOSS, E.L.; CECHETTI, D. et al. Potencial de genótipos de aveia para duplo propósito. Revista Brasileira de Agrociência, v.7, n.1, p.22-28, 2001.

SCHEFFER-BASSO, S.M.; AGRANIONIK, H.; FONTANELI, R.S. Acúmulo de biomassa e composição bromatológica de milhetos das cultivares comum e africano. Revista Brasileira de Agrociência, v.10, n.4, p.483-486, 2004. 